\title{
Does ABRACADABRA Help Improve the English Reading Ability of Chinese Elementary School Students? A Quasi- Natural Experimental Study
}

\author{
Hui Gu, ${ }^{1}$ Jijun Yao, ${ }^{1}$ Ping Bai, ${ }^{2}$ Longjun Zhou, ${ }^{3}$ \\ Alan C.K. Cheung, ${ }^{4}$ Philip C. Abrami ${ }^{5}$
}

1. Nanjing Normal University, Nanjing 210024, Jiangsu, China

2. Huajie Education Group, Lianyungang 222100, Jiangsu, China

3. Jiangsu Second Normal University, Nanjing 210013, Jiangsu, China

4. The Chinese University of Hong Kong, Hong Kong 999077, China

5. Concordia University, Montreal, Québec, H3H 2S2, Canada

\begin{abstract}
ABRACADABRA (abbreviated as ABRA) is a software developed by Concordia University in Canada that focuses on natural spelling and aims to improve English reading ability. This research is based on 129 first graders, 213 second graders, and 275 third graders in the elementary school of Lianyungang Ganyu Huajie Bilingual School. We carried out a one-semester pre-and post-test and quasi-natural experimental research design to explore the effect of $A B R A$ on students of different grades. The study results showed that ABRA improved students' abilities in all grades to varying degrees, but the impact of the first graders got the most significant. The results of classroom observations and interviews with teachers showed that teachers needed to apply systematic teaching strategies and the control of class attention play a key role in it. To improve students' English ability, teachers need to effectively improve their ability to apply information technology, especially in English class. Particularly in low-grade classrooms, attention should be paid to the management of class discipline to maintain its efficiency.
\end{abstract}

Science Insights Education Frontiers 2021; 9(2):1221-1240.

Doi: 10.15354/sief.21.or041

How to Cite: Gu, H., Yao, J., Bai, P., Zhou, L., Cheung, A.C.K., \& Abrami, P.C. (2021). Does ABRACADABRA help improve the English reading ability of 
Gu et al. ABRA Improves the English Reading of Chinese Elementary Students.

Chinese elementary school students? A quasi-natural experimental study. Science Insights Education Frontiers, 9(2):1221-1240.

Keywords: English Learning, E-Learning Software (ABRA), English Teaching, Elementary School, Experimental Research

About the Authors: Hui Gu, School of Educational Science, Nanjing Normal University, Nanjing 210024, Jiangsu, China.E-mail: gu_nnu@163.com

Ping Bai, Huajie Education Group, Lianyungang 222100, Jiangsu, China. E-mail:2691285308@qq.com

Longjun Zhou, School of Educational Science, Jiangsu Second Normal University, Nanjing 210013, Jiangsu, China. E-mail:294437034@qq.com

Alan C.K. Cheung, Department of Educational Administration and Policy, The Chinese University of Hong Kong, Hong Kong 999077, China. E-mail: alancheung@cuhk.edu.hk

Philip C. Abrami, Centre for the Study of Learning and Performance, Concordia University, Montreal, Québec, H3H 2S2, Canada.E-mail: philipc.abrami@concordia.ca

Correspondence to: Jijun Yao, School of Educational Science, Nanjing Normal University, Nanjing 210024, Jiangsu, China.E-mail: yaojijun njnu@163.com

Funding: This study was supported by Nanjing Normal University's horizontal project "High-quality school construction based on evidence-based education research" (S11060A41805). This article was also funded by the Priority Academic Program Development of Jiangsu Higher Education Institution (PAPD).

Conflict of Interests: None.

(C) 2021 Insights Publisher. All rights reserved.

cc) (i) (2) Creative Commons Non Commercial CC BY-NC: This article is distributed under the terms of the Creative Commons Attribution-NonCommercial 4.0 License (http://www.creativecommons.org/licenses/by$\mathrm{nc} / 4.0 /$ ) which permits non-commercial use, reproduction and distribution of the work without further permission provided the original work is attributed by the Insights Publisher. 


\section{Introduction}

$\mathrm{R}$ EGARDING the formation and development of children's second language, there have been studies from the perspectives of linguistics and sociolinguistics explaining the related factors and stages. The mother tongue transfer theory believed that mastery of the mother tongue would affect the second language learners' writing discourse organization, writing process and order, and language cognitive ability through the mother tongue's cultural thinking, knowledge, or ability (Wang \& Wen, 2004). However, the effect varies with the degree of grammatical similarity between the mother tongue and the second language, especially the differences in pronunciation, vocabulary, and grammar. Chinese has a negative transfer effect on English learners ( $\mathrm{Su}$, 2000). Investigation and research have also found that the native language ability of Chinese college students plays a restrictive role in the transfer of English writing ability (Wang \& Wen, 2004). In response to this, researchers start from the level of cognitive psychology and propose the steps of attention, memory, thinking, information processing, mother tongue transfer, and interlanguage formation in the process of language learning, taking the processing of interlanguage in the process of language development as the key (Wu, 2000).

Paivio's dual coding theory believes that a single sensation can only store a limited amount of information. The combination of visual and auditory stimuli can be an essential means for children to retain information (Mak et al., 2017). E-learning software fits the feature precisely. In recent years, the impact of educational information technology on the learning process and results and behavior of teachers and students, has received increasing attention. Many studies have affirmed the role of e-learning software in optimizing the educational process, increasing student engagement in learning, and enhancing teachers' teaching capabilities (Chen \& Zhao, 2017; Gu et al., 2016; $\mathrm{Li}, 2016)$. It is its advantage that e-learning software can actively stimulate attention and memory with dynamic images and sound interaction (Fan, 2014). Primarily based on games' natural integration and mobile characteristics, e-learning software can significantly improve students' learning interest and engagement, which is particularly effective in English learning. Integrating the effects of e-learning software on students, Chueng \& Slavin's meta-analysis results also found that information technology has positive impact on students $(\mathrm{d}=0.16)$, implying the great potential of e-learning software in students' language learning (Cheung \& Slavin, 2012).

Many studies with electronic teaching software were carried out in class to find out the effect on students' abilities. Among them, ABRACADABRA (abbreviated as "ABRA") software has achieved remarkable results. Its full name is "A Balanced Reading Approach for Children Always Designed to Achieve Best Results for All." Wood evaluated 20 types of English learning software in terms of shape, letter knowledge, phoneme awareness, word-sound relationship, decoding ability, reading fluency, text comprehension, etc., and believes that ABRA has a better overall performance (Wood et al., 2017). So far, ABRA software has carried out fruitful experiments in Canada, Australia, Hong Kong, China, Hunan and Nanjing $\underline{\underline{1}}$, and other regions and countries 
(Comaskey et al., 2009; Deault et al., 2009; Di Stasio et al., 2012; Wolgemuth et al., 2014; Mak et al., 2017; Wang \& Wen, 2004). Abrami integrated experiments from different countries and territories. It did not conduct a country-based subgroup analysis of the included literature based on its unity of experiment organization and implementation and the consistency of comprehensive sample results. However, the results in the ability variables show that there are potential factors that affect the differences in each experiment (Abrami et al., 2015). At the same time, existing studies have found significant heterogeneity in the experimental results of electronic information technology in different countries and regions (Cheung \& Slavin, 2012). This research was based on the cooperation of Nanjing Normal University, Jiangsu Second Normal University, the Chinese University of Hong Kong, and Concordia University in Canada. A survey was conducted on the Lianyungang Huajie Bilingual School, a private school with relatively abundant development space in China's more developed provinces. During the implementation, ABRA members of Concordia University in Canada introduced the design concept of ABRA software and the experience of implementation and teacher training in Canada, Australia and Kenya. Members of the Chinese University of Hong Kong introduced the implementation of ABRA software in Hong Kong and the focus of experimental research. Nanjing Normal University and Jiangsu Second Normal University mainly integrated the experiences of all parties to investigate the school and design experimental programs. This study aimed to explore another feasible path for the application of ABRA software in the local Chinese context.

\section{Literature Review and Questioning}

ABRA software is web software developed by Centre for the Study of Learning and Performance (CSLP) of Concordia University in Canada to improve student's English reading ability. It won the United Nations Best Learning Software Award in 2016. ABRA software is based on the six core skills of English reading ability proposed by the National Reading Panel (NRP): (1) Phoneme recognition skills: students can associate and correspond to the pronunciation of English letters and words; (2) Phoneme awareness: the ability of students to distinguish and colloquially extract single syllables from words; (3) Fluency: students can read English text quickly and expressively; (4) Reading comprehension: understanding and retelling text content; (5) Listening comprehension: understanding and retelling spoken language content; and (6) Vocabulary knowledge: recognize and understand the meaning of spoken words and text words. According to the activity needs of teachers, students, and parents, it sets up three main modules to guide the direction of activities of different groups (Abrami et al., 2015). Student module activities are the main content, including 17 "learning in doing" games. It takes natural phonics as the core, sets up games of different difficulty levels, and other activities related to reading fluency, reading comprehension, and writing: the parent module and teacher module difficulty levels. Among them, the content of the parent module mainly includes reading suggestions and reading materials for students at home; the content of the teacher module primarily consists of the teacher's teaching materials 
and teaching guidance. Through the allocation of roles and tasks and the control of game content, ABRA can help students choose their learning progress according to their own situation and get timely feedback. Teachers can keep abreast of the situation of students at any time, and parents can participate in the overall development of student progress.

The experimental research of ABRA software first focused on the countries where English is the native language. The subjects of the experiment were young children who are just beginning to learn the English language. One of the experimental studies with the largest sample size is Savage et al., based on 1,067 preschool and elementary school first- and second-year students in 74 classes in Alberta, Ontario, and Quebec. The study results found that students in the experimental group generally performed better after one semester of use than schools in the control group. It is particularly prominent in item phoneme combination $(\mathrm{p}<0.01)$, syllable-letter matching $(\mathrm{p}<$ 0.01 ), and fluency of phoneme decomposition ( $\mathrm{p}<0.01$ ) (Savage et al., 2013). Studies have also compared the characteristics of students and found that boys in the experimental group are significantly higher in sentence comprehension, paragraph comprehension, and total scores than boys in the control group. At the same time, girls do not show this difference (Abrami et al., 2016).

In some areas with official second language, researchers made some attempts to help students with different language capabilities improve English language through ABRA software. Wolgemuth et al. found that after a minimum of 120 minutes of intervention per week, the English reading development of indigenous students gradually kept pace with the non-indigenous peoples. In addition, indigenous students who have also used ABRA software are more advanced in terms of word reading and phoneme awareness. Researchers believe that this is due to the ceiling effect of the students of indigenous peoples in phoneme learning, which fully demonstrates that ABRA software can help students with weaker English foundation in the English language environment (Wolgemuth, 2019). ABRA software has also conducted some research in non-English speaking countries. The researcher took students with lower social and economic backgrounds in Kenya as the research objects. They found that after 13 weeks of using ABRA software. Students were improved in vocabulary and phonetics, as well as English, mathematics, science, and social subjects (Abrami, 2016). The Hong Kong experiment is similar to the previous experiments in English-speaking, second-language parallel, and non-English-speaking regions, indicating the beneficial effects of ABRA software. However, the research of Mak et al. discussed the variables of teacher attitudes and teacher teaching behavior. They believe that teachers' innovative application of ABRA software, effective teaching content, and high attitude and interest will help teachers play their role in software applications and promote students' performance (Mak, 2017).

To integrate the effects of ABRA software in different countries and periods, Abrami et al. conducted a meta-analysis of 11 related experiments from Australia, Canada, and China. They found that the overall effect size was 0.179. Among the six skills, improving listening comprehension $(\mathrm{g}=0.381)$ and phoneme awareness $(\mathrm{g}=0.324)$ has 
the most significant effect. At the same time, Abrami believes that the organization and implementation of these experiments are homogeneous, and therefore did not subanalyze the reasons for the differences in performance of these studies (Abrami, 2015). Based on the above research, it can be seen that ABRA software has a particular effect on the improvement of students' abilities, but the degree could change according to related factors.

Most existing research explores the software implementation process, methods, and results combined with teachers' teaching methods and strategies. Although the students' gender, economic background, and other factors are discussed, there is a lack of comparison. At the same time, according to the critical period hypothesis of second language learning, students have a certain critical period for second language learning. Still, researchers do not have a consistent conclusion on the boundary of the critical period (Snow \& Hoefnagel-Höhle, 1978). Therefore, it is necessary to discuss the English learning progress of students of different grades. At the same time, in the existing research in China, there is a lack of experimental research on electronic teaching software to improve student's English ability (or second language learning ability). Based on American positivism research tradition and methodology, evidence-based research has gradually become the mainstream of its educational research paradigm. This paradigm emphasizes the design of the quantitative analysis, experimental research, and discussion of causality and related relationships. It aims to seek the best evidence and provide specific practical approaches for school reform.

In the few existing experimental studies, due to the lack of standardization of experimental design, insufficient scientific measurement tools, and improper data processing methods, the scientificity and robustness of the conclusions are difficult to guarantee (Lei, 2007).

In response to this, this study used ABRA software to carry out experiments. In comparison, the software had undergone the scientific and rigorous software tools tested by previous experiments. Its framework design, content arrangement, and testing tools had been fully demonstrated and continuously improved in the conclusions. At present, preliminary research has been carried out in many countries and regions around the world. Therefore, the study will take Ganyu Huajie Bilingual School in Lianyungang City, Jiangsu Province, as an example, focusing on students' performance in graders of one, two, and three and different teachers' teaching strategies. We used ABRA software to explore the path and best plan for computer technology to assist students in improving their English proficiency in the Chinese context.

\section{Research Design and Methodology}

To explore the improvement of the English ability of elementary school students by the ABRA project, this study adopted a pre-test and post-test quasi-experimental research design. The study conducted a mixed research design and didn't change the existing class framework to implement the experiment. Through qualitative research, random classroom observations were conducted on the teachers of the experimental group and 
the control group. After the experimental intervention, the three experimental group teachers and the English group lesson preparation directors were interviewed to understand the teacher's feelings, attitudes, and other influencing factors to explore the experimental results and the causes and mechanisms of differences between the groups. The intervention period was the second semester of the 2018-2019 school year, from February 26, 2019, to June 14, 2019, which lasted 16 weeks.

\section{Subjects}

The research team included 956 students in 24 classes from Grade 1 to Grade 3 of Ganyu Huajie Bilingual School in Lianyungang City, Jiangsu Province. In class grouping, to avoid the "observer effect" from affecting the students in the control group, none of the teachers in the experimental class participated in the teaching process of the control class. The study included four classes in the first grade, three classes in the second and third grades, with a total of 398 people as the experimental group. Conversely, four classes were included in the first grade and four in the second and third grades, with 558 students as the control group. The conditions of the 23 classes participating in the experiment were the same, and there were no significant differences in grades, family background, and gender structure.

To ensure the accuracy of the calculation of experimental results, this study first deleted the invalid pre-test and post-test questionnaires and obtained 726 valid pretest papers and 772 post-test questionnaires. The effective questionnaire rates were $81.06 \%$ and $75.94 \%$. Considering the rationality of the arrangement of testers during the experimental test and the adaptability of elementary school students to unfamiliar questions, the return rate of this questionnaire is still within a reasonable range. Secondly, to focus on the changes in each student's performance and avoid the resulting error caused by the student transferring, dropping out of the experiment, or having only one test score, student matching was performed on the before and after test scores after invalid scores were deleted, and finally a total of 614 effective questionnaires were obtained (Figure 1).

\section{Selection and Training of Teachers in Experimental Group}

Teachers were randomly divided into experimental group or control group. Experimental members follow the school's system of dividing classes according to student scores every year to ensure that each type is equally divided. Therefore, no additional pairing was made between the participating teachers and the class to ensure that the experiment was natural. The number of teachers in experimental groups and control groups were shown in Table 1. There was no significant difference in teaching year and lesson preparation between teachers in experimental group and control group.

In the intervention, teachers' training was only for teachers in the experimental group. Trainings were divided into online and offline methods. Online communication 
Gu et al. ABRA Improves the English Reading of Chinese Elementary Students.

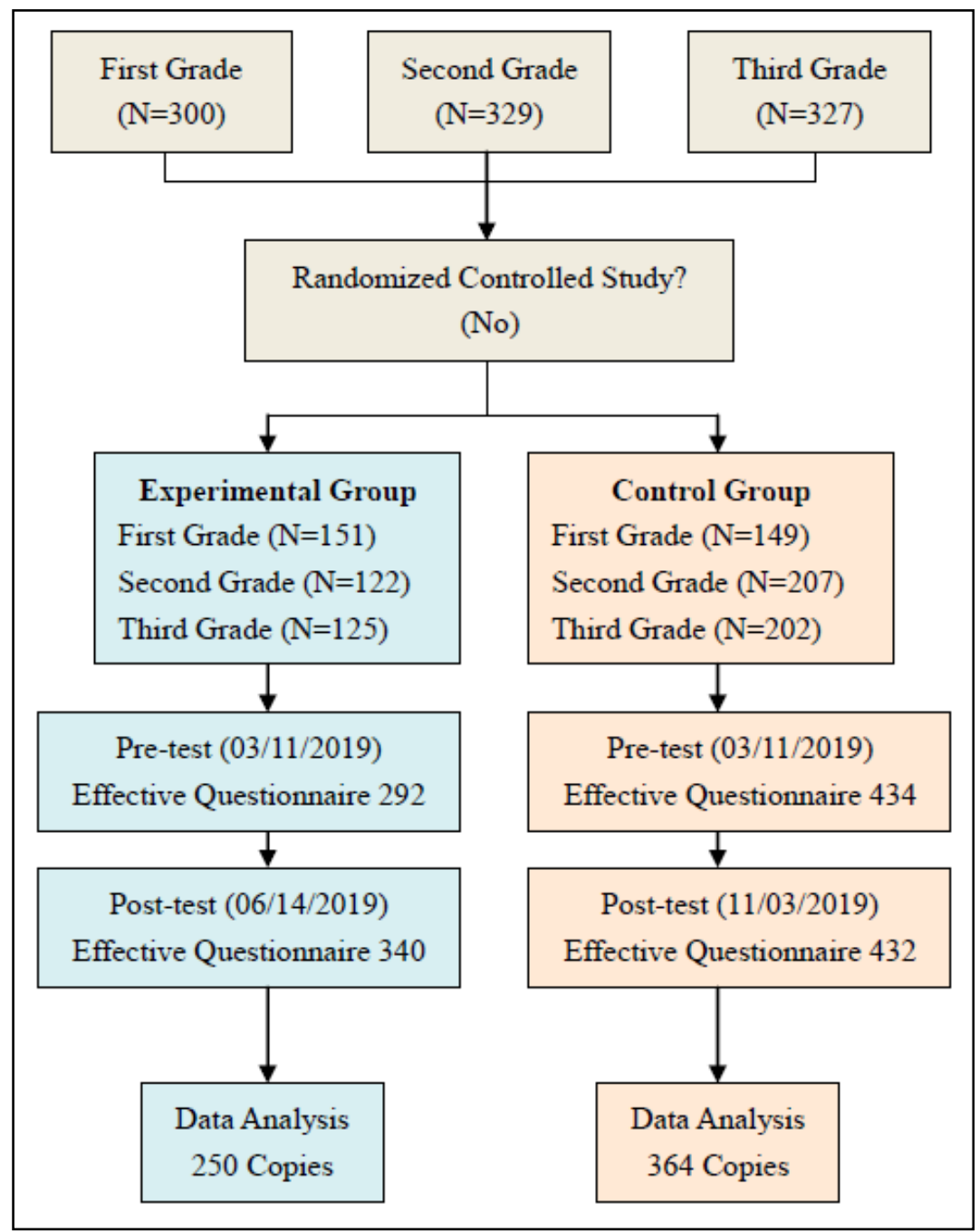

Figure 1. The Graph of the Number of Students in the Experimental Group and the Control Group.

focused on real-time answers to questions and sharing teaching materials and experience; offline discussions focused on possible problems and problem-solving strategies after the ABRA game was applied in reality. Teacher training was mainly divided into three stages. The first stage of teacher training started in February 2019. The research team formally established an online communication channel and entered the school to meet face-to-face with teachers to communicate about the background of the game and the design of the game itself. The second training phase began in April 2019, focusing on the teacher's solution to operational problems. After observing the classroom, the teachers of the experimental group discussed and made suggestions on the time alloca- 
Table 1. Comparison of the Class Allocation and the Number of Students between the Experimental Group and the Control Group.

\begin{tabular}{lllllll} 
& \multicolumn{3}{c}{ Experimental Group } & \multicolumn{3}{c}{ Control Group } \\
\cline { 2 - 7 } & Teacher & Class \# & Total Student \# & Teacher & Class \# & Total Student \# \\
\hline $\begin{array}{l}\text { First } \\
\text { Grade }\end{array}$ & $\mathrm{A}$ & 4 & 151 & $\mathrm{D}$ & 4 & 149 \\
\hline $\begin{array}{l}\text { Second } \\
\text { Grade }\end{array}$ & $\mathrm{B}$ & 3 & 122 & $\mathrm{E}$ & 3 & 121 \\
\cline { 2 - 7 } & & & & $\mathrm{F}$ & 2 & 86 \\
\hline Third & $\mathrm{C}$ & 3 & 125 & $\mathrm{G}$ & 3 & 120 \\
\cline { 2 - 7 } Grade & & & & $\mathrm{H}$ & 2 & 82 \\
\hline
\end{tabular}

tion, operation, student attention, and systemic aspects of the teaching process. The third stage of the school training started in May 2019. This stage focused on motivating teachers and summarizing the situation, avoiding the slack mentality of teachers at the end of the experimental stage and the pressure of the final exam.

\section{Teacher Intervention}

Teachers in the experimental and control groups had the following differences in teaching content, including class organization, and teaching methods. In terms of the content and teaching method, the control group teachers were required that the class continue to follow the Elementary School English Curriculum Standard (2011 Edition) and completed the textbook content per the related courses. The experimental group teachers were required to teach the Phonics method through the ABRA game, requiring no less than 80 minutes of intervention time per month. The specific intervention time depended on the teacher's teaching rhythm. The experimental group teachers also adopted the class teaching system in class organization, mainly set up as the teaching link of "teacher question-student answer-teacher summary". In terms of specific operations, the teachers in the three grades fully considered the different learning stages of the students in the three grades, and their teaching focuses were different. Based on the English foundation of the students in each grade, the first-grade teachers focused on using the natural phonemes in the game to consolidate the writing and pronunciation of the letters. The second-grade teachers attached great importance to expanding words in games and improving students' interest in English learning. The third-grade teachers paid more attention to the classification, regularity, and way of summarizing comments.

\section{Research Tools}

This study used the Group Reading and Assessment and Diagnostic Evaluation (GRADE) standardized questionnaire developed with Canadian language and education 
measurement experts. It was primarily conducted in the United States, France, India, Canada, Denmark, and other countries. It has been recognized by international counterparts and has a scientific and authoritative standardization test of English proficiency. Its standardized scope can cover the mastery of English reading skills from preschool children to adults and aims to help the students improve their English ability in the assessment. The test paper is divided into eight parts, which test the ability of students to master the same (different) words required for natural spelling, the ability to recognize rhymes, matching syllables and letters of the first and last letters in a word, letter recognition, and first and last syllable recognition. The questionnaire has a high degree of internal consistency (0.95-0.99), replica reliability (0.81-0.94), and test-retest reliability (0.80) (Williams, 2001).

The research team also used unstructured interviews. For example, interviews were conducted on teachers' teaching methods, self-rating, ABRA game application attitude, ABRA software suggestions, etc., to better analyze the results of each grade.

\section{Analysis Method and Power Estimation}

To determine the difference between the experimental and control groups after the intervention, this study calculated the effect size to reflect the effect of the ABRA game on students' English ability improvement. The effect size calculation formula is:

$$
d=\frac{m_{\text {post }-t}-m_{\text {pre-t }}}{s_{t}}-\frac{m_{\text {post }-c}-m_{\text {pre-c }}}{s_{c}}
$$

Among them, $d$ represents the experimental effect, that is, the effect size of the experimental group minus the effect size of the control group. The effect size of the experimental group is the difference between the mean of the post-test and the pre-test, divided by the combined standard deviation. $m_{\text {post }-t}$ and $m_{\text {pre- } t}$ represent the mean value of the experimental group's post-test and the experimental group's pre-test, respectively. $s_{t}$ represents the combined standard deviation of the experimental group. The effect size calculation process of the control group is the same as that of the experimental group.

In order to verify whether the sample size reaches the necessary statistical test power, we selected the effect size $d=+0.20$ and statistical test power $r^{2}=0.80$ that showed that the effect has policy influence. The power test result showed that $80 \%$ of the test power could be guaranteed with a sample size of more than 200 (Wu \& Wen, 2011).

\section{Results}

In What Works Clearhouse (WWC), a comprehensive website of educational evidence designed by the Institute of Education Sciences (IES) in the United States, to ensure that the effect size accurately reflects the impact of experimental measures on students and to reduce the great difference in students' cognitive models for the experimental error, 
the effect size of the vast difference between the experimental group and the control group was set to be less than 0.25 (Clearinghouse, 2020).

The results of the pre-post test difference between the experimental group and the control group in this study showed that in the overall difference between control group and experimental group was less than 0.25 , which is a slight difference. Thus, it showed that the difference of pre- test was effectively controlled (Table 2).

\section{English Test Results}

The effect on grade one, two and three was different The performance improved a lot in the first and third-grade students, and the first-grade students benefited the most. The ABRA game did not significantly affect the second-grade students. The following part will be based on the specific analysis of the performance of each grade on each test item.

First grade. The first-grade students have made significant progress in all items in the GRADE test (except for recognizing the same words and recognizing syllables in the last letter). Among them, the matching of notes at the end of words and recognition of letters was a significant effect $(\mathrm{d}=0.83, \mathrm{~d}=0.80)$. In addition, considerable progress has been made in word rhyme $(\mathrm{d}=0.58)$, word-initial matching $(\mathrm{d}=0.73)$, as well as different word recognition and initial listening recognition (Table 3).

Second grade. After the ABRA game, the second-year students did not achieve significant progress in each GRADE test item. There was only a tiny effect on the recognition of different words. Because the statistics were not substantial, it was impossible to reject the null hypothesis; there was no significant difference between the two groups in different word recognition abilities after the intervention (Table 4).

Third grade. In general, the third-grade students progressed after receiving GRADE game intervention, but word-initial matching showed insignificant effect size results. However, it has improved recognizing the same word, different dishes, and letter matching at the end of a word, letter recognition, and syllable recognition of the first (final) letter. Especially in the word rhyme $(\mathrm{d}=0.43)$, the improvement effect of students' performance was the greatest (Table 5).

\section{Classroom Observations Results}

There were significant differences between the introduction of ABRA games and the traditional classroom teaching mode on teachers and students in the classroom observation results.

In the course of teachers' teaching, the experimental group teachers showed attention to pronunciation. They were more active in letter pronunciation, syllables, and word memory links, and they had fewer professional errors such as misspellings and mispronunciations in presentations. In the form of teaching, the activities of ABRA could be used flexibly to stimulate students' interest in English learning. They could be combined with books to expand and consolidate words. The teachers in the control group paid more attention to the interpretation of the meaning and the repeated reading 
Table 2. The Pre-Test Differences between Experimental Group and Control Group.

\begin{tabular}{llllll} 
& \multicolumn{2}{l}{$\begin{array}{l}\text { Experimental Group } \\
(\mathbf{N = 2 5 0 )}\end{array}$} & \multicolumn{2}{c}{$\begin{array}{l}\text { Control Group } \\
\text { (N=364) }\end{array}$} & Cohen's d \\
\hline Test Item & Mean & SD & Mean & SD & 0.20 \\
\hline Total Score & 39.26 & 7.85 & 40.74 & 6.90 & 0.00 \\
\hline Same Word Recognition & 4.84 & 0.51 & 4.84 & 0.56 & 0.19 \\
\hline Different Word Recognition & 3.80 & 0.62 & 3.89 & 0.38 & 0.01 \\
\hline Word Rhyme & 4.85 & 1.80 & 4.88 & 2.02 & 0.01 \\
\hline Match the First Letter of a Word & 3.57 & 1.65 & 3.59 & 1.38 & -0.01 \\
\hline Match the Last Letter of a Word & 3.89 & 1.69 & 3.88 & 1.65 & 0.28 \\
\hline Letter Recognition & 7.92 & 2.76 & 8.63 & 2.40 & 0.20 \\
\hline Initial Syllable Identification & 5.61 & 1.85 & 5.94 & 1.48 & 0.21 \\
\hline Last Letter Syllable Discrimination & 4.79 & 1.63 & 5.11 & 1.49 \\
\hline SD: Standard Deviation. & & & & & 0 \\
\hline
\end{tabular}

Table 3. Changes in First Grade English Scores.

\begin{tabular}{|c|c|c|c|c|c|}
\hline \multirow[b]{2}{*}{ Test Item } & \multicolumn{2}{|c|}{$\begin{array}{l}\text { Experimental } \\
\text { Group (N=67) }\end{array}$} & \multicolumn{2}{|c|}{$\begin{array}{l}\text { Control } \\
\text { Group }(\mathrm{N}=59)\end{array}$} & \multirow[b]{2}{*}{ Cohen's o } \\
\hline & Pre-test & Post-test & Pre-test & Post-test & \\
\hline Total Score & $\begin{array}{l}30.52 \\
(5.77)\end{array}$ & $\begin{array}{l}38.15 \\
(7.77)\end{array}$ & $\begin{array}{l}33.68 \\
(5.37)\end{array}$ & $\begin{array}{l}36.05 \\
(8.05)\end{array}$ & $0.77^{\star \star \star}$ \\
\hline Same Word Recognition & $\begin{array}{l}4.78 \\
(0.67)\end{array}$ & $\begin{array}{l}4.55 \\
(1.05)\end{array}$ & $\begin{array}{l}4.8 \\
(0.66)\end{array}$ & $\begin{array}{l}4.66 \\
(0.91)\end{array}$ & -0.08 \\
\hline Different Word Recognition & $\begin{array}{l}3.61 \\
(0.81)\end{array}$ & $\begin{array}{l}3.45 \\
(1.03)\end{array}$ & $\begin{array}{l}3.9 \\
(0.3)\end{array}$ & $\begin{array}{l}3.64 \\
(0.86)\end{array}$ & 0.22 \\
\hline Word Rhyme & $\begin{array}{l}3.99 \\
(1.66) \\
\end{array}$ & $\begin{array}{l}5.55 \\
(2.05) \\
\end{array}$ & $\begin{array}{l}4.53 \\
(1.67) \\
\end{array}$ & $\begin{array}{l}5.05 \\
(2.27) \\
\end{array}$ & $0.58^{* *}$ \\
\hline Match the First Letter of a Word & $\begin{array}{l}2.66 \\
(1.37) \\
\end{array}$ & $\begin{array}{l}2.96 \\
(1.21) \\
\end{array}$ & $\begin{array}{l}2.81 \\
(0.98) \\
\end{array}$ & $\begin{array}{l}2.31 \\
(1.05) \\
\end{array}$ & $0.73^{\star * *}$ \\
\hline Match the Last Letter of a Word & $\begin{array}{l}2.79( \\
1.54)\end{array}$ & $\begin{array}{l}3.31 \\
(1.41)\end{array}$ & $\begin{array}{l}2.93 \\
(1.42)\end{array}$ & $\begin{array}{l}2.32 \\
(1.28)\end{array}$ & $0.80^{\star \star *}$ \\
\hline Letter Recognition & $\begin{array}{l}5.39 \\
1.95) \\
\end{array}$ & $\begin{array}{l}7.3 \\
(2.46) \\
\end{array}$ & $\begin{array}{l}6.2 \\
(2.33) \\
\end{array}$ & $\begin{array}{l}6.27 \\
(2.67) \\
\end{array}$ & $0.83^{\star * \star}$ \\
\hline Initial Syllable Identification & $\begin{array}{l}3.67 \\
(1.68) \\
\end{array}$ & $\begin{array}{l}6.01 \\
(1.71) \\
\end{array}$ & $\begin{array}{l}4.39 \\
(1.5) \\
\end{array}$ & $\begin{array}{l}6.19 \\
(1.95) \\
\end{array}$ & 0.35 \\
\hline Last Letter Syllable Discrimination & $\begin{array}{l}3.64 \\
(1.44)\end{array}$ & $\begin{array}{l}4.82 \\
(1.65)\end{array}$ & $\begin{array}{l}4.12 \\
(1.39)\end{array}$ & $\begin{array}{l}5.42 \\
(1.82)\end{array}$ & -0.05 \\
\hline
\end{tabular}




\section{Table 4. Changes in Second Grade English Scores.}

\begin{tabular}{|c|c|c|c|c|c|}
\hline \multirow[b]{2}{*}{ Test Item } & \multicolumn{2}{|c|}{$\begin{array}{l}\text { Experimental } \\
\text { Group }(\mathrm{N}=77)\end{array}$} & \multicolumn{2}{|c|}{$\begin{array}{l}\text { Control } \\
\text { Group (N=136) }\end{array}$} & \multirow[b]{2}{*}{ Cohen's o } \\
\hline & Pre-test & Post-test & Pre-test & Post-test & \\
\hline Total Score & $\begin{array}{l}40.94 \\
(5.87) \\
\end{array}$ & $\begin{array}{l}46.96 \\
(8.96) \\
\end{array}$ & $\begin{array}{l}38.04 \\
(5.26) \\
\end{array}$ & $\begin{array}{l}49.53 \\
(5.16) \\
\end{array}$ & $-1.41^{* * *}$ \\
\hline Same Word Recognition & $\begin{array}{l}4.83 \\
(0.47)\end{array}$ & $\begin{array}{l}4.78 \\
(0.75)\end{array}$ & $\begin{array}{l}4.84 \\
(0.53)\end{array}$ & $\begin{array}{l}4.89 \\
(0.34)\end{array}$ & -0.2 \\
\hline Different Word Recognition & $\begin{array}{l}3.86 \\
(0.53)\end{array}$ & $\begin{array}{l}3.91 \\
(0.4)\end{array}$ & $\begin{array}{l}3.84 \\
(0.49)\end{array}$ & $\begin{array}{l}3.83 \\
(0.54)\end{array}$ & $0.13^{\star * *}$ \\
\hline Word Rhyme & $\begin{array}{l}5.09 \\
(1.56) \\
\end{array}$ & $\begin{array}{l}8.97 \\
(3.01) \\
\end{array}$ & $\begin{array}{l}4.2 \\
(1.89) \\
\end{array}$ & $\begin{array}{l}8.31 \\
(2.01) \\
\end{array}$ & $-0.49^{* * *}$ \\
\hline Match the First Letter of a Word & $\begin{array}{l}4.58 \\
(1.6) \\
\end{array}$ & $\begin{array}{l}3.68 \\
(1.2) \\
\end{array}$ & $\begin{array}{l}3.45 \\
(1.3) \\
\end{array}$ & $\begin{array}{l}3.81 \\
(1.15)\end{array}$ & $-0.94^{* \star *}$ \\
\hline Match the Last Letter of a Word & $\begin{array}{l}4.32 \\
(1.52)\end{array}$ & $\begin{array}{l}4.62 \\
(1.34)\end{array}$ & $\begin{array}{l}3.34 \\
(1.53)\end{array}$ & $\begin{array}{l}5.18 \\
(1.02)\end{array}$ & $-1.22^{* \star *}$ \\
\hline Letter Recognition & $\begin{array}{l}6.73 \\
(1.92) \\
\end{array}$ & $\begin{array}{l}7.88 \\
(2.53) \\
\end{array}$ & $\begin{array}{l}7.45 \\
(1.83) \\
\end{array}$ & $\begin{array}{l}8.68 \\
(1.94) \\
\end{array}$ & $-0.14^{\star \star *}$ \\
\hline Initial Syllable Identification & $\begin{array}{l}6.22 \\
(1.15)\end{array}$ & $\begin{array}{l}6.94 \\
(1.13)\end{array}$ & $\begin{array}{l}5.92 \\
(1.45)\end{array}$ & $\begin{array}{l}7.43 \\
(0.7)\end{array}$ & -0.7 \\
\hline Last Letter Syllable Discrimination & $\begin{array}{l}5.3 \\
(1.49)\end{array}$ & $\begin{array}{l}5.61 \\
(1.5)\end{array}$ & $\begin{array}{l}5.01 \\
(1.49)\end{array}$ & $\begin{array}{l}6.63 \\
(1.07)\end{array}$ & $-1.03^{\star \star \star}$ \\
\hline
\end{tabular}

\section{Table 5. Changes in Third Grade English Scores.}

\begin{tabular}{|c|c|c|c|c|c|}
\hline \multirow[b]{2}{*}{ Test Item } & \multicolumn{2}{|c|}{$\begin{array}{l}\text { Experimental } \\
\text { Group }(\mathrm{N}=106)\end{array}$} & \multicolumn{2}{|c|}{$\begin{array}{l}\text { Control } \\
\text { Group (N=169) }\end{array}$} & \multirow[b]{2}{*}{ Cohen's d } \\
\hline & Pre-test & Post-test & Pre-test & Post-test & \\
\hline Total Score & $\begin{array}{l}43.58 \\
(5.5)\end{array}$ & $\begin{array}{l}48.53 \\
(6.0) \\
\end{array}$ & $\begin{array}{l}45.37 \\
(5.07)\end{array}$ & $\begin{array}{l}48.6 \\
(5.4) \\
\end{array}$ & $0.24^{\star *}$ \\
\hline Same Word Recognition & $\begin{array}{l}4.88 \\
(0.43)\end{array}$ & $\begin{array}{l}4.93 \\
(0.25)\end{array}$ & $\begin{array}{l}4.85 \\
(0.54)\end{array}$ & $\begin{array}{l}4.83 \\
(0.59)\end{array}$ & 0.19 \\
\hline Different Word Recognition & $\begin{array}{l}3.88 \\
(0.51)\end{array}$ & $\begin{array}{l}3.84 \\
(0.58)\end{array}$ & $\begin{array}{l}3.93 \\
(0.29)\end{array}$ & $\begin{array}{l}3.83 \\
(0.63)\end{array}$ & 0.15 \\
\hline Word Rhyme & $\begin{array}{l}5.23 \\
(1.87)\end{array}$ & $\begin{array}{l}8.18 \\
(2.36)\end{array}$ & $\begin{array}{l}5.54 \\
(2.02)\end{array}$ & $\begin{array}{l}7.64 \\
(2.32)\end{array}$ & $0.43^{* * *}$ \\
\hline Match the First Letter of a Word & $\begin{array}{l}3.42 \\
(1.45)\end{array}$ & $\begin{array}{l}3.43 \\
(1.03)\end{array}$ & $\begin{array}{l}3.96 \\
(1.43)\end{array}$ & $\begin{array}{l}3.7 \\
(1.14)\end{array}$ & 0.22 \\
\hline Match the Last Letter of a Word & $\begin{array}{l}4.26 \\
(1.59)\end{array}$ & $\begin{array}{l}4.08 \\
(1.41)\end{array}$ & $\begin{array}{l}4.64 \\
(1.46)\end{array}$ & $\begin{array}{l}4.34 \\
(1.31)\end{array}$ & 0.09 \\
\hline Letter Recognition & $\begin{array}{l}10.38 \\
(1.34)\end{array}$ & $\begin{array}{l}10 \\
(1.28)\end{array}$ & $\begin{array}{l}10.42 \\
(1.22)\end{array}$ & $\begin{array}{l}10.09 \\
(1.08)\end{array}$ & 0.00 \\
\hline Initial Syllable Identification & $\begin{array}{l}6.4 \\
(1.44)\end{array}$ & $\begin{array}{l}7.36 \\
(1.06)\end{array}$ & $\begin{array}{l}6.49 \\
(1.06)\end{array}$ & $\begin{array}{l}7.22 \\
(1.01)\end{array}$ & 0.05 \\
\hline Last Letter Syllable Discrimination & $\begin{array}{l}5.14 \\
(1.48)\end{array}$ & $\begin{array}{l}6.08 \\
(1.4)\end{array}$ & $\begin{array}{l}5.53 \\
(1.35)\end{array}$ & $\begin{array}{l}6.41 \\
(1.07)\end{array}$ & -0.07 \\
\hline
\end{tabular}

Note: The asterisk ${ }^{*}$ indicates the result in the independent sample $t$ test, ${ }^{*} p<0.1,{ }^{* *} p<0.05,{ }^{* * *} p<0.01$. 
of words and texts. They did not pay much attention to the role of activities in English learning.

In terms of student performance, the students in the experimental group showed more enthusiasm for English learning, were willing to improve their English ability in activities, and showed extremely high sensitivity in word pronunciation and syllable reflection. Compared with the students in the control group, the students in the experimental group were more fluent in reading texts and words; they mastered more quickly in performance and sentence comprehension; they did not show too much fear in the face of unfamiliar words and sentences patterns. On the other hand, the experimental group had some difficulties in class organization. Students were particularly excited about the activities they were interested in. Therefore, teachers in the experimental group needed to maintain classroom discipline and focus students' attention on teaching knowledge.

\section{Teacher Interview Results}

To understand the role of teachers in the use of ABRA games, this study further designed semi-structured interviews. We interviewed the experimental group teacher $\mathrm{A}$, teacher B, teacher C, and director D of the English teaching and research section in the first, second, and third grades. To further analyze the teacher's application of the software in preparation, class, after class, and the teacher's psychological state.

The changes in the psychological state of the teachers were relatively consistent, which was a change from semi-acceptance to acceptance to active integration. The second-grade teacher B said frankly, "I didn't teach very carefully at the beginning. It was not until your second visit that I prepared more seriously and used it more." The underlying reason was that teachers were more or less burnout due to heavy tasks. The first-grade teacher A also said that this was an important reason he could not fully accept the ABRA game initially. She took half of the first-grade class (4 classes), a class of about 40 students, and "If a child's learning foundation is weak and sometimes feels that it is too late to complete the task of the textbook." Teacher C worried, "I am afraid that the grades of our third-grade students will fall in the city's unified exam."

After the first stage of use and the second stage of training, teachers generally responded well. Because I found that "some syllables can also be memorized together with words in the book" (Teacher A); "Students are particularly interested and feel that they can teach students interesting English" (Teacher B); and "I am also familiar with ABRA, unlike It was so difficult at the beginning" (Teacher C). In the third stage, teachers had their innovative understanding of games. The first-grade teacher A felt that "using the game of Same Words, sometimes we could review the words we have learned", and found that this was not just an English tool that can only be played.

In the interaction with students and student feedback, teachers said that students like this software very much. "Sometimes I don't need to say, when I was about to open this software, they would shout 'ABRA time' together." (Teacher B) "Because they liked it so much, they suddenly became noisy and I found it hard to keep the disci- 
pline." (Teacher B) Moreover, Teacher B also said that sometimes "Students pay all their attention to the game, and we had no time to explain the knowledge in the games." Teacher A also thought that some words are still too difficult for first-grade students and can only be skipped or introduced roughly. It is difficult for students to remember and apply after class. Many of them were a bit like left-behind children, because their parents were too busy at work, and grandparents could take them to play at home"(Director D) and "the family background is not good, most of the homes do not own computers" (Teacher A, Teacher B, Teacher C)

In this study, the experimental results of the second grade were not ideal, and the teacher interviews also deliberately explored the reasons. Teacher B of the secondyear experimental group also expressed his thoughts on the experimental results of the first semester. "When teachers in the control group were teaching words, they would consciously use natural phonics to their students." This showed that the students in the second-grade control group were also exposed to natural phonics. Although there were two random classroom observations, teachers who could know in advance usually wanted to "have something to show" (Director D), so they avoided vocabulary teaching in the classroom observation class and focused on the reading and performance of the text. Therefore, the two classroom observations found no signs of using natural spelling by the teachers in the control group.

Teachers also had some opinions on the improvement of the software, especially in picture books. In terms of the display form of picture books, "Students are not very interested in picture books; they just look at the pictures and read. If there are vivid animations, and be shorter, students could learn easier." (Teacher B) Regarding the difficulty of the picture book, Teacher $\mathrm{C}$ believed that the content of the picture book was too straightforward sometimes but too tricky for the third-grade students, so it was too difficult to make a correct choice. I hope that the school could build the computer room as soon as possible, because "if students play by themselves, it will be better than I teach them how to play. At that time, it will be difficult to manage discipline and teach one by one" (Teacher B).

\section{Conclusion and Discussion}

The study results found that ABRA software teaching positively affects students' English, especially phoneme awareness. On the one hand, the results confirmed that natural spelling, as an intermediary for second language acquisition, can decode words to deepen students' vocabulary memory, improving spelling, writing, and reading comprehension abilities (Peng \& Tao, 2009). At the same time, it is consistent with the research conclusions of teaching natural phonics in the Chinese context, which proves the universality of natural phonics to improve students' pronunciation (Jiang, 2016). On the other hand, the research results support the positive effects of e-learning software on students after being used in the classroom. Based on the double coding theory, the information organization form of the combination of audio-visual can retain complete information so that students can better full reading in animation than static images. At 
the same time, the storage space of each channel is limited. As each type of storage space has a mutually independent memory system, vision and hearing can become "assistants" to each other's memory (Mak, 2017).

However, the performance of each grade is not the same. From the point of view of the progress value of the experimental group itself from the post-test to the pretest alone, the progress of grade one to grade three tends to decrease gradually. Studies have shown that 5-7 years old is a crucial period for children's word order development, and students' native language ability will continue to grow at this stage. The work to be done in the stage of mother tongue transfer becomes more complicated, and the difficulty of second language learning will increase (Qi, 2009). From the point of view of the software effect size of the control group and the experimental group, the research results show that the experimental group of the first grade has made the most progress; followed by the experimental group of the third grade. The reason may be the first and second-grade teachers' excessively active phoneme intervention. In teacher interviews and reflections on practical training, the research team found that the second-grade control group teachers understand natural spelling. She has a mentality of "not falling behind" after the teachers of the experimental group started the natural spelling experiment. Therefore, the teaching of "natural spelling" was also increased in the class so that the experimental group of the second grade did not show more advantages as a whole. Second, student attention was closely related to second language acquisition based on electronic software. Compared with students in the first and third grades, second-year students can quickly learn the games in the classroom after a preliminary understanding of English. However, since there is no suggestion of complete rule awareness in the class, it is often difficult for students to maintain teaching discipline in ABRA games. At the same time, students will not concentrate on learning phoneme knowledge points but only pay attention to the game links, which affects the secondgrade students' acquisition of ABRA learning effects (Ding, 2012).

The overall results of students in each item were also consistent with the research results of Jiang's application of natural phonics to third-grade vocabulary teaching. The students in the experimental group had superior performance in vocabulary spelling and spelling, phonetic awareness, and vocabulary selection ability (Jiang, 2016). More specifically, students have improved their letter matching ability and phoneme recognition ability to a greater extent, which was also consistent with the performance of Mak's various topics (Mak, 2017). The difference in the speed of progress in multiple fields is that, on the one hand, the teacher focuses on the listening discrimination of phonemes according to the level and stage of the students' natural phonics during the teaching process. On the other hand, due to identifying initial and ending letters and matching the beginning and end of words, students need to come up with the word's correct spelling in their minds and then look for the correct answer on the test paper. Students will fail to choose the correct answer because they cannot recall the right words or recall them promptly. Mak et al. also mentioned that students of second language learning need to construct brand-new words in their brains in some questions, which will increase the difficulty of the questions (Mak, 2017). 


\section{Study Limitations and Perspectives}

Based on natural spelling, this research is aimed at Ganyu Huajie Bilingual School in Lianyungang City, Jiangsu Province, on the ABRACADABRA software. It is found that teaching based on electronic software can significantly improve students' English ability. This proves the applicability of the "quoted" e-teaching software and the natural spelling teaching method in the local English teaching process and also shows the positive role of promoting school digital teaching. It is also a reasonable attempt to build a "college-school partnership". However, the implementation effect of e-teaching will vary due to the school's software/hardware conditions, teachers' teaching style, and teachers' mastery and understanding of e-teaching. Moreover, in this project, due to the limitations of funds, time and personnel, the experiment failed to fully guarantee the "non-intervention" behavior of the teachers in the control group. Therefore, although the research conclusion proves the practical function of natural spelling and ABRA software, this deficiency affects the robustness of the local findings to a certain extent.

In the future English teaching process, we should first teach natural spelling in the lower grades. The study results found that the progress of lower-grade students is more significant than that of upper-grade students. Educators should abandon the prejudice of low-grade students' low learning efficiency and weak adaptability, and they need to face up to the plasticity of low-grade students. Teachers need to pay attention to the transfer of knowledge in the game and establish the awareness of students' rules in the interaction between teachers and students to enhance students' interest. The process of e-learning should be promoted. The research results support the positive impact of audio-visual multi-dimensional electronic teaching tools on student performance. Schools should actively arrange funds to upgrade electronic teaching software, strengthen the training of teachers in the use of electronic teaching, and strive to strengthen teachers' teaching levels and promote the diversification of teaching methods. Teachers should also avoid "playing games for the sake of games" in the teaching process. It is necessary to clarify teaching objectives, apply teaching methods rationally, and strengthen systematic and efficient instruction.

The importance of experimental research lies in the ability to provide detailed experimental procedures and results for evaluation. The accumulation of experimental research can provide educators with effective and comprehensive teaching strategies, reducing new programs" "trial and error" costs. On this basis, comprehensive and systematic teaching measures can provide principals, teachers, and students with effective experimental programs in many aspects and help education policymakers' reference. This research presents a relatively standard experimental process to promote the development of experimental research in the direction of education. Based on the continuous improvement and advancement of experiments in English learning, more and more verifiable application models of English e-teaching software will be developed in the future. In the case of meeting the development needs of students, we should pay attention to the applicability and comprehensiveness of software and electronic applications in local contexts while adapting to the differences between schools and teachers. 
Gu et al. ABRA Improves the English Reading of Chinese Elementary Students.

Notes

1. The experimental reports of Hunan and Nanjing have not yet been published.

\section{References}

Abrami, P.C., Wade, C.A., Lysenko, L., Marsh, J., \& Gioko, A. (2016). Using educational technology to develop early literacy skills in Sub-Saharan Africa. Education and Information Technologies, 21(4):945-964. DOI: https://doi.org/10.1007/s10639-014-9362-4

Abrami, P., Borohkovski, E., \& Lysenko, L. (2015). The effects of ABRACADABRA on reading outcomes: A meta-analysis of applied field research. Journal of Interactive Learning Research, 26(4):337-367. DOI: https://www.learntechlib.org/primary/p/1473 $\underline{96 /}$

Chen, Y., \& Zhao, K. (2017). The effect of information technology on the scientific selfefficacy of middle school students. Open Education Research, 23(6):60-70. [Chinese] DOI:

https://doi.org/10.13966/i.cnki.kfjyyj.2017.0 6.007

Cheung, A.C.K., \& Slavin, R.E. (2012). How features of educational technology applications affect student reading outcomes: A meta-analysis. Educational Research Review, 7(3):198-215. DOI:

https://doi.org/10.1016/j.edurev.2012.05.002

Clearinghouse, W.W. (January, 2020). What Works Clearinghouse Standards Handbook, Version 4.1. Washington, DC: U.S. Department of Education, Institute of Education Sciences, National Center for Education Evaluation and Regional Assistance. https://ies.ed.gov/ncee/wwc/Docs/referencer esources/WWC-Standards-Handbook-v4-1508.pdf

Comaskey, E.M., Savage, R.S., \& Abrami, P. (2009). A randomised efficacy study of Web - based synthetic and analytic programmes among disadvantaged urban Kindergarten children. Journal of Research in Reading, 32(1): 92-108. DOI:

https://doi.org/10.1111/j.1467-

9817.2008.01383.x

Deault, L., Savage, R., \& Abrami, P. (2009). Inattention and response to the ABRACADABRA web-based literacy intervention. Journal of Research on Educational Effectiveness, 2(3):250-286. DOI:

https://doi.org/10.1080/19345740902979371

Di Stasio, M.R., Savage, R., \& Abrami, P.C. (2012). A follow-up study of the ABRACADABRA web-based literacy intervention in Grade 1. Journal of Research in Reading, 35(1):69-86. DOI:

https://doi.org/10.1111/j.14679817.2010.01469.x

Ding, J., Pan, F., Wang, Y., \& Chen, Y. (2012). The effect of 9 to 13-year-old pupils' attention on academic performance. Medical Journal of Communications, 26(6):569572+579. [Chinese] DOI: https://doi.org/10.3969/j.issn.1006$\underline{2440.2012 .06 .016}$

Fan, L. (2014). Research on the influence of dynamic geometry software on students' attention. Dissertation; Liaoning Normal University. [Chinese] DOI: https://doi.org/10.7666/d.Y2612733

Gu, X., Wang, C., \& Wang, F. (2016). Has the role of information technology happened? A study on the influence of education information. e-Education Research, 37(10):5-13. [Chinese] DOI: https://doi.org/10.13811/j.cnki.eer.2016.10.0 $\underline{01}$ 
Gu et al. ABRA Improves the English Reading of Chinese Elementary Students.

Jiang, N. (2016). Research on the Application of Natural Phonics in Third Grade English Vocabulary Teaching. Dissertation; Shenyang Normal University. [Chinese] http://cdmd.cnki.com.cn/article/cdmd10166-1016112890.htm

Lei, Y. Research on the effect of computerassisted teaching software on pupils' memorizing English words under the network environment. Inner Mongolia Normal University, 2007. [Chinese] DOI: https://doi.org/10.7666/d.y1173539

$\mathrm{Li}$, L. (2016). Research on the influence of ICT application ability of middle school chemistry teachers on the effectiveness of teaching interaction. Dissertation; Central China Normal University, 2016. [Chinese] http://cdmd.cnki.com.cn/Article/CDMD10511-1016271076.htm

Mak, B.S.Y., Cheung, A.C.K., Guo, X., \& Abrami, P.C. (2017). Examining the impact of the ABRACADABRA (ABRA) webbased literacy program on primary school students in Hong Kong. Education and Information Technologies, 22(6):2671-2691. DOI: https://doi.org/10.1007/s10639-0179620-3

Peng, P., \& Tao, S. (2009). The role of word decoding, English language comprehension and general cognitive abilities in Chinese children's English reading learning. Foreign Language Teaching and Research, 41(1):3037+80-81. [Chinese]

http://www.cnki.com.cn/Article/CJFDTotalWJYY200901007.htm

Qi, W. (2009). Retrospect of the study of children's language in my country. Journal of Nanjing University of Posts and Telecommunications (Social Science Edition), 11(1):54-59. [Chinese] DOI: https://doi.org/10.14132/j.cnki.nysk.2009.01. 002

Savage, R., Abrami, P.C., Piquette, N., Wood, E., Deleveaux, G., Sanghera-Sidhu, S., \& Burgos, G. (2013). A (Pan-Canadian) cluster randomized control effectiveness trial of the ABRACADABRA web-based literacy program. Journal of Educational Psychology, 105(2):310-328. DOI: https://psycnet.apa.org/doi/10.1037/a003102 5

Snow, C.E., \& Hoefnagel-Höhle, M. (1978). The critical period for language acquisition: Evidence from second language learning. Child Development, 49(4):1114-1128. DOI: https://doi.org/10.2307/1128751

$\mathrm{Su}, \mathrm{L}$. (2000). The impact of mother tongue transfer on second language learning. Journal of Beijing International Studies University, 7(4):44-52. [Chinese] http://www.cnki.com.cn/Article/CJFDTotalJDEW200004009.htm

Wang, L., \& Wen, Q. (2004). The transfer of native language proficiency to second language writing: cross-language rationale and path. Foreign Language Teaching and Research, 48(3):2 05-212+241. [Chinese] DOI: https://doi.org/10.3969/j.issn.10000429.2004.03.006

Williams, K.T. (2001). Group reading assessment and diagnostic evaluation. American Guidance Service.

Wolgemuth, J.R., Abrami, P.C., Helmer, J., Savage, R., Harper, H., \& Lea, T. (2014). Examining the impact of ABRACADABRA on early literacy in Northern Australia: An implementation fidelity analysis. The Journal of Educational Research, 107(4):299-311. DOI:

https://doi.org/10.1080/00220671.2013.8233 $\underline{69}$

Wolgemuth, J.R., Savage, R., Helmer, J., Harper, H., Lea, T., Abrami, P.C., Kirby, A., Chalkiti, K., Morris, P., Carapetis, J., \& Louden, W. (2013). ABRACADABRA aids Indigenous and non-Indigenous early literacy in Australia: Evidence from a multisite randomized controlled trial. Computers \& Education, 67:250-264. DOI: https://doi.org/10.1016/j.compedu.2013.04.0 02

Wood, E., Grant, A.K., Gottardo, A., Savage, R., \& Evans, M.A. (2017). Software to promote young children's growth in literacy: A comparison of online and offline formats. Early Childhood Education Journal, 45(2):207-217. DOI: https://doi.org/10.1007/s10643-016$\underline{0779-9}$ 
Gu et al. ABRA Improves the English Reading of Chinese Elementary Students.

Wu, Q. (2000). Cognitive psychoanalysis on the process of second language acquisition. Foreign Language Teaching and Research, 44(4):290-295. [Chinese]

http://www.cnki.com.cn/Article/CJFDTotalWJYY200004009.htm
Wu, Y., \& Wen, Z. (2011). Statistical analysis process related to null hypothesis testing. Psychological Science, 34(1):230-234. [Chinese] DOI:

https://doi.org/10.16719/j.cnki.1671$\underline{6981.2011 .01 .038}$

Received: 06 August 2021

Revised: 09 August 2021

Accepted: 17 August 2021 